\title{
UM ESTUDO SOBRE O RACIOCÍNIO LÓGICO MATEMÁTICO: O CASO DAS OLIMPÍADAS DE PROGRAMAÇÃO DE COMPUTADORES
}

\author{
Valéria Espíndola Lessa - IFRS Campus Erechim - lessavaleria@ gmail.com \\ Ariane Mileidi Pazinato - IMED Passo Fundo - ariane.mileidi@ gmail.com \\ Adriano Canabarro Teixeira - Universidade de Passo Fundo - teixeira@upf.br
}

\begin{abstract}
Resumo. Este artigo apresenta os resultados de um estudo sobre o uso do raciocínio lógico matemático de estudantes do ensino fundamental participantes das Olimpíadas de Programação de Computadores. O referencial teórico está embasado na informática educativa e na psicologia cognitiva. É uma pesquisa de cunho qualitativo a partir da análise das produções destes estudantes e das percepções deles sobre a atividade de programar. Os instrumentos de coleta de dados constituíram-se em gravação dos arquivos gerados após as resoluções e as entrevistas em grupo focal. A análise dos dados deu-se através da identificação, nas falas e nas produções, da relação de ordem e planejamento, indicativa de raciocínio lógico. Como resultados, temos que a relação de ordem e planejamento perpassa todo o processo de programação e que, portanto, a programação de computadores demanda o desenvolvimento do raciocínio lógico.
\end{abstract}

Palavras-chave: Raciocínio lógico matemático. Programação de Computadores. Olimpíadas.

\section{A STUDY ON MATHEMATICAL LOGICAL REASONING: THE CASE OF COMPUTER PROGRAMMING OLYMPICS}

\begin{abstract}
This paper presents the results of a study on the use of mathematical logical reasoning by elementary students participating in the Computer Programming Olympiads. The theoretical framework is based on educational informatics and in cognitive psychology. It is a qualitative research based on the analysis of the productions from these students and their perceptions on the activity of programming. The data collection instruments were constituted by file records generated after the resolutions and by the focus group interviews. The analysis of the data occurred through the identification, over the lines and productions, in the relation of order and planning, indicative of logical reasoning. As results, we have that the relation of order and planning pervades the whole process of programming and that, therefore, the computer programming demands the development of the logical reasoning.
\end{abstract}

Keywords: Mathematical Logical Reasoning. Computer Programming. Olympiads.

\section{Introdução}

Vivemos hoje na era das tecnologias digitais e das sociedades complexas, as quais têm desencadeado mudanças nos modos de comunicação, de acesso às informações e, consequentemente, em relação ao saber na sociedade atual (LÉVY, 2010). Neste sentido, dada a importância de ações que possibilitem a exploração do potencial destas novas tecnologias na educação, compreender as implicações do seu uso educacional e, especificamente, no desenvolvimento do raciocínio lógico, apresenta-se como uma temática de pesquisa relevante. Nessa perspectiva, surge o interesse em analisar o V. $15 \mathrm{~N}^{\circ} 2$, dezembro, 2017 
potencial do uso de softwares de programação por crianças em idade escolar para o desenvolvimento do raciocínio lógico matemático.

Para tanto, este trabalho constitui-se a partir de um estudo de cunho qualitativo, em que procuramos identificar, nas soluções programadas pelos estudantes e nas suas falas, relações de ordem e planejamento, como indícios do uso do raciocínio lógico matemático. Para isso, selecionamos como base de análise um dos desafios realizados por eles na Olimpíada de Programação de Computadores para Estudantes do Ensino Fundamental e constituímos um grupo focal com quatro estudantes a fim de realizar entrevistas abertas.

\section{A programação de computadores a partir da informática educativa}

Falar em programação de computadores requer delimitar em qual sentido estamos usando o termo. Tecnicamente, podemos dizer que programar é um processo de escrita que gera um programa de computador e o objetivo desta ação está no produto final. Porém, em nossa perspectiva, avançamos no que se refere a um processo mecânico para chegar num fim específico. Nos aliamos a ideias que consideram o ato de programar uma atividade criativa, reflexiva e com potencial de aprendizagem e de desenvolvimento cognitivo, em que o interesse deve estar no processo e não no fim.

Com isso, apoiamos nossos estudos na informática educativa desenvolvida principalmente por Seymour Papert no início dos anos de 1970 quando, enquanto pesquisador do Massachusetts Institute of Technology (MIT), criou a linguagem de programação Logo, destinada a crianças. Seus projetos, baseados na psicologia cognitiva de Piaget, objetivavam saber como as crianças poderiam aprender a pensar melhor a partir das tecnologias. E foi então que desenvolveu sua Teoria Construcionista.

A linguagem Logo, permite a construção de "micromundos", desenvolvendo habilidades que utilizam diferentes conhecimentos, principalmente conhecimentos matemáticos. Porém, não são os conhecimentos na forma de conteúdos escolares formais. São conhecimentos que possuem aplicação e sentido para a criança. Para o autor, é o engajamento pessoal na situação a ser resolvida que poderá gerar uma melhor aprendizagem (PAPERT, 2008, p.37).

Para Papert (1997), a criança pode programar um computador ensinando-o. E, ao "ensinar o computador a pensar", a criança embarca numa exploração sobre a maneira como ela própria pensa e como ela irá fazer para construir sua programação. Neste processo, vários fatores estão envolvidos e dentre eles o raciocínio lógico que é necessário na elaboração das sentenças e na verificação das condições de verdade na execução do programa. "Pensar sobre modos de pensar faz a criança tornar-se um epistemólogo, uma experiência que poucos adultos tiveram" (PAPERT, 1997, p.35).

Seguindo estas ideias Construcionistas e continuando os trabalhos que Papert realizava no MIT, o grupo Lifelong Kindergarten no Media Laboratory, liderado por Mitchel Resnick, vem desenvolvendo novas tecnologias a fim de propiciar às pessoas, especialmente crianças, experiências de aprendizagens criativas. Neste sentido, em maio de 2007, foi lançado o Software de Programação Scratch, com uma interface colorida, dinâmica e de fácil manipulação. Segundo Resnik et al (2009), o principal objetivo do Scratch não é formar programadores profissionais, mas cultivar uma nova geração de pessoas criativas que usam programação para expressar suas ideias. Assim,

the core audience on the site is between the ages of eight and 16, though a sizeable group of adults participates as well. As scratcher program and share interactive projects, they learn important mathematical and computational concepts, as well as how to think creatively, reason systematically, and work 
collaboratively: all essential skills for the 21th century. (RESNICK et al, 2009, p.60)

Nossa opção em trabalhar com o Scratch nas Olimpíadas de Programação e, consequentemente, nesta investigação, se deu em função de sua interface dinâmica e atraente à faixa etária dos alunos participantes, além de possibilitar o compartilhamento de projetos tornando públicas as construções realizadas pelos alunos. O Scratch é um software no qual é possível criar jogos, histórias animadas e outros programas interativos. Ele não exige o conhecimento prévio de outras linguagens de programação e é ideal para pessoas que estão começando a programar. A tela inicial do software, na versão 1.4, utilizada nesta pesquisa, pode ser visualizada por meio da Figura 1.

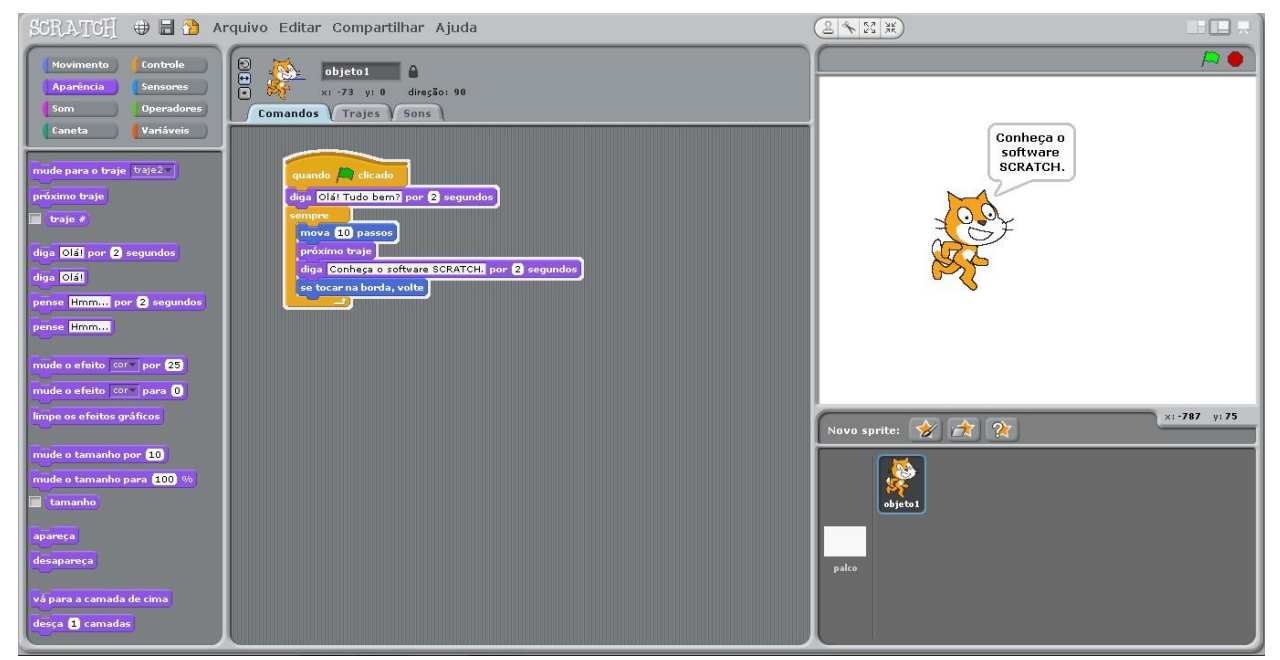

Figura 1 - Tela inicial do Scratch 1.4

Fonte: Arquivos dos autores.

O Scratch faz uso de uma forma de programação simples, colorida e em blocos (comandos prontos na forma de blocos que devem ser arrastados e organizados), voltada para crianças e jovens, onde é possível construir projetos que desenvolvam suas habilidades matemáticas e de programação.

Percebendo a importância de explorar e fortalecer a relação existente entre o ato de programar e o desenvolvimento do raciocínio lógico matemático, avançamos no tópico seguinte explicitando o que entendemos por raciocínio lógico matemático e de que forma o seu desenvolvimento está relacionado com a programação de computadores.

\section{Aprendizagem e desenvolvimento de raciocínio lógico matemático}

Antes de avançarmos para as questões metodológicas, precisamos deixar claro nossas perspectivas sobre aprendizagem e sobre o desenvolvimento do raciocínio lógico matemático, elementos tão caros para nossa investigação. E, para isso, trazemos as ideias de Constance Kamii (1988) desenvolvidas e ancoradas a partir dos estudos de Piaget.

Segundo Kamii (1988), Piaget estabeleceu a distinção entre três tipos de conhecimentos: o conhecimento físico, o social e o lógico matemático. O conhecimento físico é tudo aquilo que as crianças reconhecem de características de objetos da realidade externa a partir da observação. Se um objeto é redondo, é fino, se cai quando é solto no ar, se faz barulho quando cai, etc. O conhecimento social são as convenções construídas pelas pessoas numa determinada cultura, como se deve agir em sociedade, as palavras que não devemos falar, as datas comemorativas, os feriados, enfim, as regras da sociedade que só podem ser aprendidas pelas crianças por intermédio dos adultos. No entanto, estes 
tipos de conhecimentos exigem estruturas mentais nas crianças que permitam o estabelecimento das diferenças entre uma coisa e outra e o estabelecimento de relações e conexões. Este processo de coordenação das relações é um movimento interno e é o chamado conhecimento lógico matemático. Para Kamii (1988),

\begin{abstract}
quando nos apresentam uma plaqueta vermelha e uma azul, e notamos a diferença, esta diferença é um exemplo de pensamento lógico matemático. As plaquetas são realmente passíveis de observação, mas a diferença entre elas não. A diferença é uma relação criada mentalmente pelo indivíduo que relaciona os dois objetos. A diferença não está nem em uma plaqueta nem em outra. Se a pessoa não colocasse os objetos dentro desta relação, para ela não existiria a diferença [...] A relação na qual uma pessoa coloca os objetos é uma decisão sua. (KAMII, 1988, p. 14)
\end{abstract}

Com isso, a criança progride no desenvolvimento de seu conhecimento lógico matemático na medida que aumenta sua capacidade de coordenar os diferentes repertórios de relações que ela estabelece mentalmente. Na coordenação de ações sobre objetos, a criança está produzindo a manipulação simbólica e o raciocínio dedutivo (MATTOS, 2012). E, neste processo de desenvolvimento, Piaget definiu dois tipos de abstração: a empírica e a reflexionante. O primeiro tipo de abstração se concentra em propriedades de objetos que estão na realidade externa, e o segundo tipo em relações que existem na realidade interna da criança, isto é, na sua mente. Ambas abstrações coexistem na criança e uma ajuda a outra.

Para clarificar o que foi dito, exemplificaremos estes dois tipos de abstrações com a ideia de construção de número, a partir de Kamii (1988). Os números, de início, são aprendidos pelas crianças a partir de conjuntos concretos de auxiliam na abstração empírica (conhecimento das propriedades físicas) e na abstração reflexionante (conhecimento das diferenças e estabelecimento de relações). Ou seja, os alunos observam os conjuntos de objetos e vão estabelecendo as relações de ordem e inclusão. Mas à medida que os números vão crescendo e fica impossível representá-los por conjuntos, a abstração reflexionante pode agir sozinha. Com as relações construídas, é possível compreender números como 1.000.000.000.002, sem que nunca tenhamos visto ou contado.

Crianças pequenas, de 4 anos, estão num nível de desenvolvimento que ainda não permite a distinção das partes do todo dos objetos. Por exemplo, ao mostrar um conjunto de 5 cães e 2 gatos em miniatura para uma criança de 4 anos e perguntarmos se há mais cães do que animais, a criança vai dizer que sim, porque neste momento ela não percebe que cães e gatos formam o conjunto de animais e que, portanto, há mais animais do que cães. Já aos 7 e 8 anos, a criança consegue realizar as relações citadas e, além disso, a maior parte do seu pensamento torna-se flexível o suficiente para ser reversível, isto é, ter habilidade de realizar operações opostas ao mesmo tempo. Para Kamii (1988), quanto mais móvel for o pensamento, mais reversível será e, portanto, mais capacidade de estabelecer relações e mais capacidade de raciocínio lógico matemático.

No mesmo sentido das ideias de Kamii (1988), Mortari (2001) afirma, de forma objetiva, que o raciocínio está relacionado com o ato de fazer inferências, que consiste em manipular as informações, fazendo conexões entre informações preexistentes e as novas recebidas. É também estruturar a ordem dos pensamentos, hierarquizando as informações e fazendo análises que apresentam resultados concebidos como informações novas. Assim, desenvolver o raciocínio lógico matemático é desenvolver capacidades cognitivas que permitem fazer inferências, estabelecer relações de ordem e planejamento, estabelecer conexões entre as coisas físicas e abstratas e estabelecer relações de reversibilidade. Ou seja, capacidades de abstração reflexionante. Assim, fomos levados a 
questionar em que sentido a programação de computadores pode estar possibilitando o uso destas capacidades e de que forma as Olimpíadas de Programação de Computadores contribuem nessa tarefa.

\title{
4. Percurso metodológico
}

Sendo o raciocínio lógico matemático um processo de coordenação mental que permite o estabelecimento de relações e conexões entre coisas físicas e abstratas, possibilitando ao sujeito a realização das tarefas mais comuns de seu dia-dia até as mais complexas e sofisticadas, como podemos analisar seu desenvolvimento? Para este estudo, fizemos a opção metodológica de investigar, nas produções e nas falas dos sujeitos de um grupo focal, uma das possíveis relações a serem desenvolvidas com a programação de computadores, a partir da sua participação nas Olimpíadas de Programação, que dê indicações sobre o uso do raciocínio lógico matemático através da manifestação de relações de ordem e planejamento, especificamente.

Neste sentido, utilizamos uma abordagem metodológica qualitativa na produção e análise dos dados, uma vez que envolve a interpretação e a compreensão das percepções dos sujeitos investigados. Concordamos com Esteban (2010) de que a pesquisa qualitativa é

\begin{abstract}
uma atividade sistemática orientada à compreensão em profundidade de fenômenos educativos e sociais, à transformação de práticas e cenários socioeducativos, à tomada de decisões e também ao descobrimento e desenvolvimento de um corpo organizado de conhecimento. (ESTEBAN, 2010, p. 127)
\end{abstract}

Os dados deste estudo foram produzidos através de entrevista aberta com os estudantes de uma das equipes que participaram das Olimpíadas e das produções deste grupo referente aos desafios das Olimpíadas. Entrevistas com grupos focais é uma técnica de produção de dados que busca estimular os participantes a discutir sobre um assunto introduzido pelo pesquisador, visando a criação de um debate sobre o tema (BONI e QUARESMA, 2005). Nesta entrevista, os assuntos eram introduzidos por meio de questionamentos orientados pelos seguintes tópicos: concepções sobre programação de computadores; relação da programação com conhecimentos formais e informais; mudanças percebidas na forma de raciocínio após a participação nas Olimpíadas. E para análise dos dados, buscamos identificar como a relação de ordem e planejamento foi evidenciada nos discursos dos sujeitos e nas produções realizadas.

A equipe escolhida para constituir tal grupo foi a equipe Escola Machado, que participou das Olimpíadas em duas edições com os mesmos integrantes. Nesta investigação, portanto, iremos analisar o desenvolvimento do raciocínio lógico matemático por meio das percepções e da produção dos quatro estudantes desta equipe no que se refere às relações de ordem e planejamento. Faremos a referência a eles por Aluno A, Aluno B, Aluno C e Aluno D.

As Olimpíadas de Programação de Computadores para estudantes do ensino fundamental, teve sua primeira edição em 2013 e desde então objetiva promover a introdução de programação de computadores no ensino fundamental, através do Scratch. É destinada aos estudantes de escolas públicas de educação básica, a partir do $6^{\circ}$ ano, de Passo Fundo e região e cada escola pode inscrever, no máximo, duas equipes, e estas devem ser compostas por um professor responsável, um professor suplente, três alunos titulares e dois alunos suplentes. As equipes foram recepcionadas num espaço preparado nas dependências da Universidade de Passo Fundo, na qual receberam orientações prévias ao início da atividade. Cada equipe recebeu um material que consistia em um envelope 
lacrado com lápis, borracha, caneta e as folhas impressas com os desafios.

Durante a competição as equipes visualizavam os desafios a serem programados e suas respectivas pontuações e realizavam a programação. Quando julgavam ter concluído alguma questão, encaminhavam-na para a avaliação da banca, que por sua vez as corrigia a partir dos critérios estabelecidos no regulamento. No caso de alguma questão não estar de acordo com o critério específico, a equipe podia reenviar o desafio para avaliação uma segunda vez. A divulgação do status dos desafios por equipe fora exposta em um painel eletrônico, onde era possível, a todas as equipes, acompanharem seu desempenho.

Ressaltamos que os desafios elaborados e propostos, foram estruturados a partir de situações que despertassem curiosidade e que explicitassem a capacidade de resolver problemas, de formular hipóteses, de formular estratégias de resolução, de comunicação sobre suas ideias, conceitos e procedimentos, tanto por meio da linguagem oral como na linguagem de programação do software.

\section{Dados obtidos e análises}

Sendo a produção da Equipe Machado muito extensa nas duas Olimpíadas, oito desafios em 2013 e quatro em 2014, escolhemos apenas um dos desafios para análise dada sua exigência cognitiva para realização: o Desafio 4 da Olimpíada de 2013. Tal escolha deuse por ter sido o desafio melhor pontuado desta equipe em $2013^{1}$. O Desafio 4, nomeado Balão Branco teve o objetivo de desafiar os estudantes a relacionar cálculos geométricos com desenho, na mesma programação. Na Figura 2 temos a ordem do exercício, juntamente com os critérios a serem avaliados e pontuados pela coordenação da competição. Na Figura 3 temos a resolução deste desafio pela Equipe Machado e na Figura 4, a tela da programação em execução.

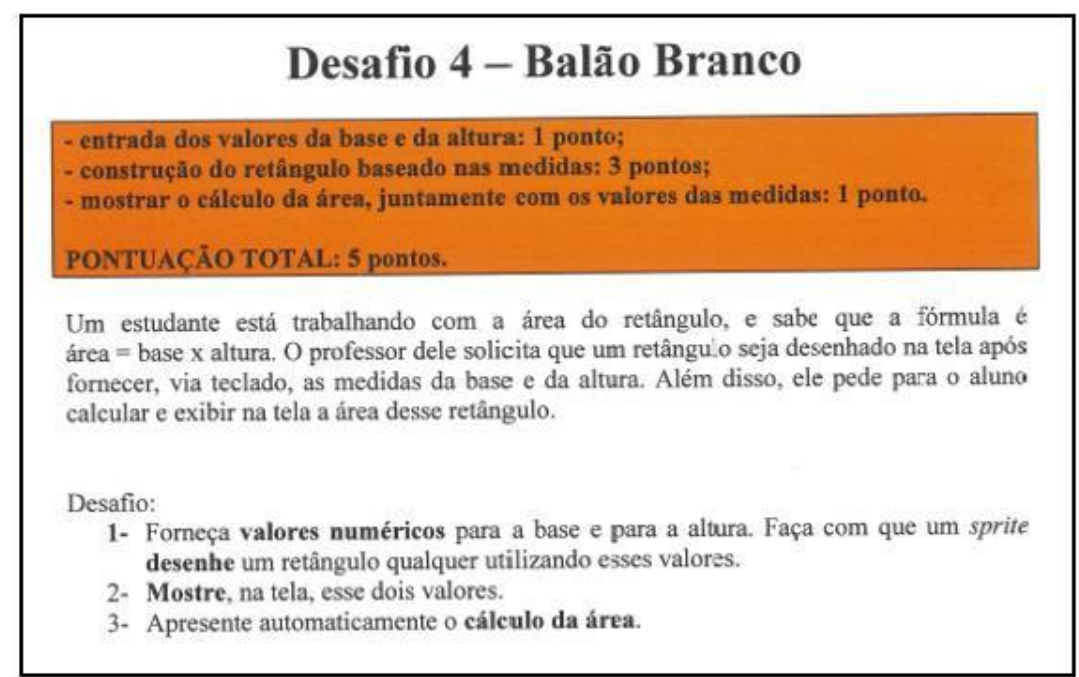

Figura 2 - Desafio 4 da Olimpíada de Programação 2013

Fonte: http://olimpiada.mutirao.upf.br/progr2013/

\footnotetext{
${ }^{1}$ Não iremos detalhar aqui todos os desafios das duas olimpíadas, neste sentido, para maiores informações acessar http://olimpiada.mutirao.upf.br/progr2013/ ou http://www.youblisher.com/p/829868Desafios-Finais-1a-Olimpiada-de-Programacao-UPF. Também é possível consultar Pazinato (2015)
} 


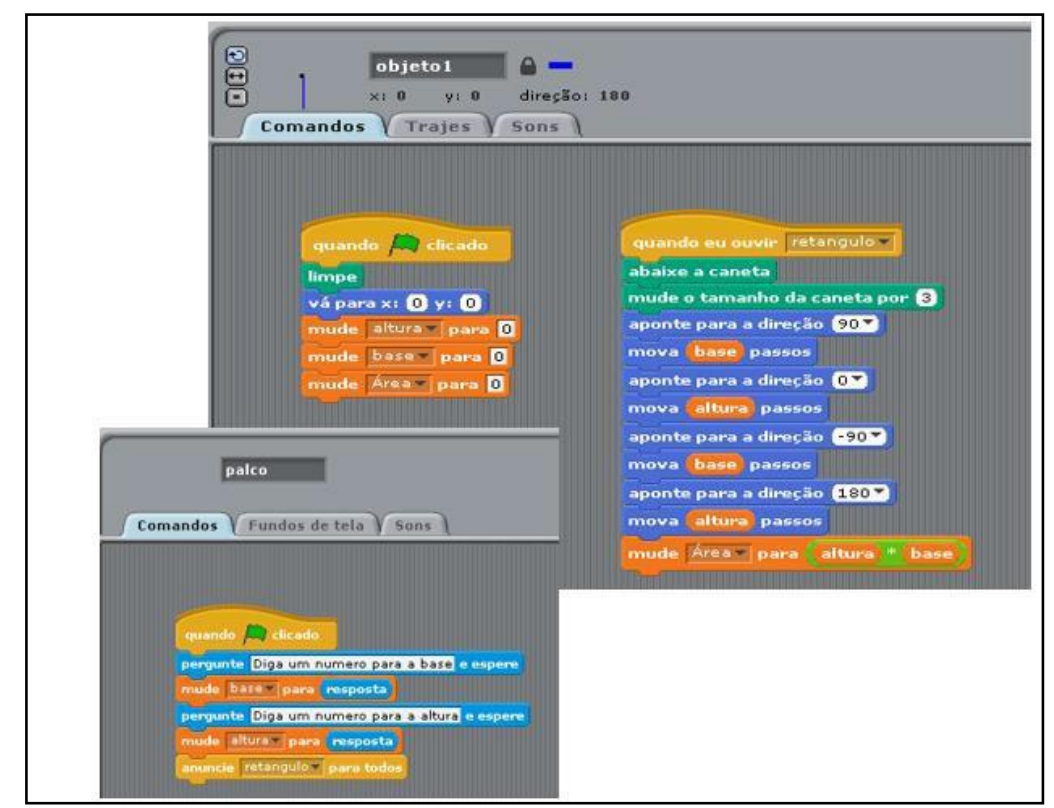

Figura 3: Tela de programação desafio 4 realizada pela Equipe Machado Fonte: Arquivos dos autores

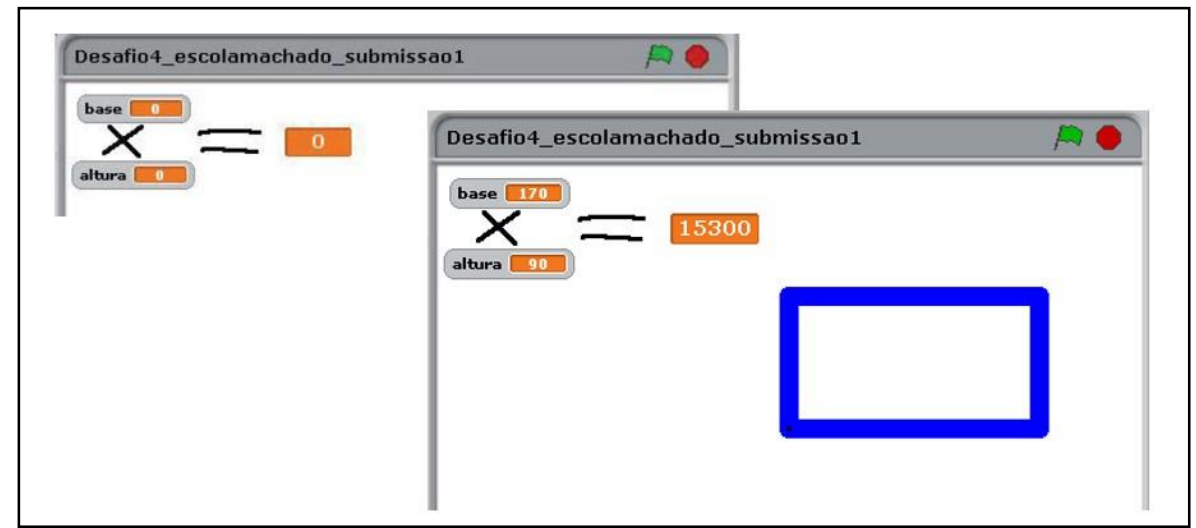

Figura 4: Tela de execução da programação do desafio 4 realizada pela Equipe Machado Fonte: Arquivos da $1^{\text {a }}$ Olimpíada de Programação.

Analisando as duas telas de programação da Figura 3, podemos inferir sobre várias relações que foram realizadas para que a programação fosse construída. Na primeira coluna da tela do objeto 1, temos a criação de três variáveis, "altura", "base" e "área" e a indicação de posicionamento inicial para o objeto que desenhou a figura. Para que o software realize cálculos, é necessário inserir valores numéricos no programa e para isso é necessário armazenar estes valores. E o armazenamento de valores é feito através de variáveis. Para que o software realize desenhos na tela, é necessário definir a posição deste na tela e a forma do risco (cor, espessura, comprimento do traço, ângulo entre um traço e outro, etc).

Na segunda coluna da tela do objeto 1, ainda na Figura 3, temos a associação do valor atribuído à "base" e à "altura" para a realização do risco na tela, usando a "caneta" com "tamanho 3". E para cada risco feito, temos a mudança de ângulo. O raciocínio para organizar este programa é pensar como se alguém estivesse posicionado numa certa direção e sentido e precisasse caminhar para formar o desenho, no caso um retângulo. Daí precisaria andar, girar, andar novamente, girar novamente e assim sucessivamente. Para realizar o cálculo, é preciso aplicar a fórmula da área de um retângulo, que foi dada no exercício, a partir das ferramentas disponíveis, ou seja, variáveis e operadores. E, o 
resultado deste cálculo, pode ser armazenado em outra variável, no caso "área".

Mas para que consigamos inserir os valores da base e altura, a fim de calcular e desenhar, o programa precisa interagir com o usuário. É necessário que o programa faça perguntas ao usuário e aguarde sua resposta. Isto pode ser observado na segunda imagem que forma a Figura 3, onde está a programação realizada para o "palco". A pergunta sobre o valor da "base" é armazenada na variável "base" e o mesmo acontece com o valor da "altura". Feito o armazenamento, o "palco" manda uma mensagem ao "objeto 1" que começa a realizar sua programação. Veja que até entre os elementos diferentes da programação é preciso estabelecer alguma espécie de vínculo.

A determinação do que é preciso fazer, a partir da ordem do desafio, com o que é possível fazer, a partir das ferramentas que o software oferece, é estabelecer relações, nos mais diferentes níveis, entre conhecimentos prévios sobre matemática, sobre geografia e sobre o Scratch para, então, criar algo. Assim, vemos que as relações de ordem entre as ações realizadas e o planejamento destas ações, como e quando devem ser realizadas, estão na base de todas as conexões que os estudantes podem estar realizando no ato de programar. Mas vejamos agora o que os estudantes manifestaram sobre isso.

Analisando os dados produzidos nas entrevistas do grupo focal, os alunos manifestaram compreender a necessidade de planejar uma sequência de comandos. Disseram que, analisando os desafios das Olimpíadas, precisavam elencar uma sequência de comandos, analisar e verificar se esta sequência estaria obedecendo realmente aos critérios exigidos no desafio. Mostravam ter consciência de que era necessário planejar como as tarefas seriam executadas, numa determinada ordem ou sequência desejada. Nessa direção, inferimos que uma relação de ordem e planejamento foi evidenciada e manifestada pelos sujeitos, tanto na análise do desafio, como nas falas. Isto é ratificado também em nossas observações durante a execução das Olimpíadas, em que alguns sujeitos da equipe faziam uma organização mental do que iria acontecer, sem o auxílio do papel. Os extratos das falas abaixo, ajudam nesta inferência:

\begin{abstract}
Para mim, programar significa criar uma sequência de dados e de movimentos para que algo aconteça. Então, você vai fazer com que algo funcione da sua maneira, programando para fazer o que você quer [...]. Eu tinha que programar na minha cabeça o que ia acontecer a cada escolha que eu fizesse, o que era certo ou não. Então, eu tinha que pensar um pouco sozinha, apesar de o grupo estar junto comigo [...]. Até em casa, quando você quer fazer a lista do mercado, você vai estruturar as suas coisas e dizer o que você quer comprar e colocar em que ordem no mercado [...]. Tipo, se o pão está perto eu vou ali e já pego. Porque isso também economiza mais tempo, fica mais rápido [...] (Aluno A).
\end{abstract}

\begin{abstract}
Você tem que pensar que jogo vai fazer e depois arrumar um jeito de fazer a programação para que esse jogo funcione de acordo com o que você acha e tal. Você não pode pegar um jogo praticamente pronto que diz tudo o que você tem que fazer. Você tem que pensar o jogo e como vai fazer, se vai mudar alguma coisa ou não (Aluno C).
\end{abstract}

Assim, é possível perceber evidências do uso de raciocínio lógico matemático na resolução dos desafios das Olimpíadas, uma vez que observamos, na ação de programar, a coordenação de relações estabelecidas mentalmente, a partir da manipulação de objetos simbólicos como as variáveis, a operação de multiplicação, os elementos da programação (palco e objeto 1) e a indicação dos movimentos e do posicionamento inicial. Também, nas falas do grupo focal, percebemos nas suas manifestações a partir das falas, elementos indicativos do uso de relações de ordem e planejamento para realizarem suas programações. 


\section{Considerações finais}

A discussão apresentada nos ajuda a considerar que o papel da educação precisa ser o de oferecer situações aos estudantes que possibilite a construção de estruturas mentais capazes de se articularem a fim de compreender o mundo e interagir com ele. Entre as possibilidades que a informática oferece à educação, a programação de computadores se apresenta como uma ferramenta diferenciada, pois possibilita a total interação da criança com a máquina na criação de "micromundos" em que muitos conhecimentos são manifestados. Segundo Papert (2008), dar sentido ao que queremos aprender possibilita aprender qualquer coisa através da ampliação de nossos repertórios de esquemas que complexifica cada vez mais nosso poder de raciocínio lógico matemático.

Finalmente, após a análise das produções do grupo focal e da manifestação de seus membros, é possível apontar que o ato de programar propiciou aos estudantes o desenvolvimento de capacidades cognitivas que os habilitam a fazer inferências estabelecendo claras relações de ordem e planejamento, através da conexão entre as coisas físicas e abstratas.

\section{Referências}

BONI, V.; QUARESMA, S. J. Aprendendo a entrevistar: como fazer entrevistas em ciências sociais? Em Tese. Revista Eletrônica dos Pós-Graduandos em Sociologia Política da UFSC, Vol. 2 nº 1 (3), Florianópolis, p. 68-80, janeiro-julho/2005.

EDUScratch. Home-page. Disponível em: < http://eduscratch.dge.mec.pt $>$. Acesso em: 30 dez. 2016.

ESTEBAM, M. P. S. Pesquisa qualitativa em educação: fundamentos e tradições. Porto Alegre: AMGH, 2010.

KAMII, C. A criança e o número: implicações educacionais da teoria de Piaget para a atuação junto a escolares de 4 a 6 anos. 7.ed. Campinas: Papirus, 1988.

LÉVY, P. As tecnologias da inteligência. Rio de Janeiro: Ed. 34, 2010.

MATTOS, S.M.N. O desenvolvimento do raciocínio lógico matemático: possíveis articulações afetivas. Caderno dá licença. v.7. Ano 10. 2012. Disponível em < http://www.uff.br/var/www/htdocs/dalicenca/images/artigo5.pdf $>\quad$ Acesso em 30.dez.2016.

MORTARI, C. A. Introdução à lógica. São Paulo, SP: UNESP, 2001.

PAPERT, S. Logo: computadores e educação. Tradução de José A. Valente, Beatriz Bitelman e Afira V. Ripper. São Paulo: Editora Brasiliense, 1985.

A família em rede. Lisboa: Relógio D'água, 1997.

. A máquina das crianças: repensando a escola na era da informática. ed. rev.

Porto Alegre: Artmed, 2008.

PAZINATO, A. M. Desdobramentos da Olimpíada de Programação de Computadores no desenvolvimento do raciocínio lógico matemático. 2015. Dissertação. [Mestrado em Educação]. Universidade de Passo Fundo. 2015. Disponível 
em <https:1/secure.upf.br/pdf/2015ArianeMileidiPazinato.pdf> Acesso em: 30.dez.2016.

RESNICK, M. et al.. Scratch: programming for all. Commrmication of the ACM. vo1.52. n.11. pp.60-67, 2009.

Disponível em http://web.media.mit.edu/mres/papers/Scratch-CACM-final.pdf> Acesso em 30.dez.2016. 